\title{
La demanda de profesionales de la información y documentación en España: Análisis de las denominaciones de las ofertas de trabajo y de las tareas y competencias profesionales que involucran
}

\author{
Juan Antonio MARTínez COMECHE \\ juan.comeche@ucm.es \\ Antonio CARPALLO BAUTISTA \\ acarpall@ucm.es \\ Esther BURGOS BORDONAU \\ eburgos@ucm.es \\ Universidad Complutense de Madrid. Biblioteconomía y Documentación \\ José María de FrANCISCO Olmos \\ josemafr@ucm.es \\ Universidad Complutense de Madrid. Ciencias y Técnicas Historiográficas y Arqueología
}

Recibido: Diciembre 2014

Aceptado: Febrero 2015

Resumen: El objetivo de este estudio es profundizar en las causas de la disminución en la demanda de formación especializada en Información y Documentación a pesar del papel cada vez más destacado que posee la información y la documentación en el mercado laboral. Se recopiló una muestra de ofertas de trabajo públicas y privadas anunciadas durante 2012 y 2013 a nivel estatal, analizando la formación exigida y las tareas o competencias profesionales asociadas a las denominaciones más demandadas. Se concluye que la formación en Biblioteconomía y Documentación es demandada cuando el puesto de trabajo está vinculado al tratamiento y gestión de documentos, mientras que nuestras titulaciones no se consideran apropiadas cuando el trabajo está relacionado con la gestión de información y con las tecnologías, ámbito laboral cada vez más relevante para nuestros egresados.

Palabras clave: Archiveros; Bibliotecarios; Competencias profesionales; Documentalistas; España; Formación académica; Mercado de trabajo; Ofertas de empleo.

Demand for Library and Information Science professionals in Spain: Analysis of the names of job offers and tasks and skills involved

Abstract: The aim of this study is to examine the causes of the decline in demand for
specialized training in Library and Information Science despite the increasingly role of
information and documentation in the labor market. A sample of public and private job offers
announced during 2012 and 2013 at the state level were collected, analyzing the academic
training, tasks and skills associated with the most frequent denominations. It is concluded that 
academic training in Library and Information Science is required when the job is linked to the treatment and management of documents, while our degrees are not considered appropriate when the work is related to information management and technology, these last jobs being more important for our graduates now and in the future.

Keywords: Academic training; Archivists; Documentalists; Job offers; Labor market; Librarians; Professional skills; Spain.

\section{INTRODUCCIÓN}

En los últimos años se viene observando una disminución en el número de alumnos que cursan los estudios de Información y Documentación en las universidades públicas españolas. Entre las posibles causas que se han apuntado destacan el aumento de las tasas académicas y la falta de visibilidad de esta profesión en nuestra sociedad (Abadal, 2013: 227), que desconoce las tareas que pueden desempeñar sus titulados o las reduce a las de bibliotecario o archivero.

Se han realizado estudios que han analizado esta situación, tratando de desentrañar las causas de esta aparente contradicción: mientras la información cobra cada vez un papel más destacado en el mundo globalizado que vivimos, disminuye la demanda de formación en esa área específica del conocimiento.

Los enfoques utilizados para analizar esta situación y sus causas han sido diversos. Es frecuente que se parta de una descripción general de la profesión, incluyendo la formación universitaria ofertada (Ortiz-Repiso; Calzada-Prado; Aportela-Rodríguez, 2013), la investigación, las asociaciones profesionales existentes (Caridad; Martín; Méndez; Rodríguez, 1999), pasando luego a analizar la inserción laboral de los titulados (Martín González; Travieso Rodríguez; Ríos Hilario; Hernández Olivera; Caro Castro, 2014), la formación y los requisitos solicitados (Montes López, 1995), así como la evolución de la oferta y de los perfiles ocupacionales en los últimos años (Abadal; Borrego; Serra Pérez, 2012). Finalmente se analizan las vinculaciones entre formación y empleo (Baiget, 2012) (Moreiro-González; Sánchez-Cuadrado; Morato-Lara; Tejada-Artigas, 2009).

En estos estudios se utilizan habitualmente datos procedentes de los propios egresados de una facultad (Borrego; Comalat; Estivill Rius, 2004), de servicios de empleo de la propia universidad (Moreiro-González, 2001), de diversos organismos públicos nacionales (Ortiz-Repiso; Calzada-Prado; AportelaRodríguez, 2013), de muestras de ofertas de empleo públicas y privadas (Montes López, 1995) o de las reflexiones de expertos manifestadas en congresos y reuniones sobre el tema (Information, 2012). En cuanto a la metodología empleada, destacan los estudios estadísticos de carácter cuantitativo, los estudios de opinión de carácter cualitativo y la participación de expertos, incluyendo en ocasiones el empleo simultáneo de varias de estas técnicas (Merlo-Vega; GómezHernández; Hernández-Sánchez, 2011). 
El objetivo de nuestro estudio es profundizar en las causas de la disminución en la demanda de formación especializada en Información y Documentación a través del análisis de las denominaciones más frecuentes empleadas en una amplia muestra de ofertas de trabajo públicas y privadas anunciadas durante los años 2012 y 2013 a nivel estatal.

Este objetivo general se desarrolla en los siguientes objetivos concretos:

1. Vincular las denominaciones demandadas con la formación previa exigida en cada una de ellas.

2. Vincular las denominaciones demandadas con las tareas concretas o competencias profesionales que los empleadores exigen en el desarrollo de los respectivos puestos de trabajo.

3. Analizar las carencias más relevantes en la titulación de grado de Información y Documentación en función de las competencias exigidas en el mercado de trabajo.

Sería deseable determinar con exactitud en qué medida estas competencias están incorporadas a los planes de estudio del grado en Información y Documentación. Sin embargo, este objetivo añadido no se afronta en el presente estudio, pues no existe un único plan de estudios para todos los grados en Información y Documentación en España.

En consecuencia, se deja este aspecto para un trabajo posterior, limitándonos en el presente análisis a comprobar hasta qué extremo el mercado laboral relaciona en los últimos años nuestra titulación con perfiles profesionales propios de la información y la documentación, por un lado, y si no fuese así, si ello se debe a carencias formativas en las competencias requeridas actualmente a los profesionales de nuestro campo, pero considerando únicamente las más destacadas y siempre con un carácter general (Baiget, 2012).

La particularidad de este estudio radica en la consideración de la denominación de las ofertas de trabajo utilizada por los empleadores como punto de partida para el análisis posterior, en lugar de basarnos en alguna clasificación a priori de los perfiles profesionales en función de las concepciones y estructuración de las tareas conforme al conocimiento teórico y empírico generado en nuestras áreas. De esta manera creemos poder observar mejor el punto de vista propio del mercado laboral, confrontándolo posteriormente al punto de vista académico.

Siguiendo con este enfoque, el análisis propuesto no es de carácter esencialmente cuantitativo o estadístico a raíz de los datos recopilados, sino que trata de profundizar en el estudio de las denominaciones más frecuentes obtenidas previamente: Community manager, Documentalista, Grabador de datos, Gestor de contenidos web, Auxiliar de biblioteca, Bibliotecario y Digitalizador. Las ofertas de empleo con estas denominaciones se distinguen de las posteriores en que, a partir de aquí, su frecuencia disminuye abruptamente configurando una larga cola de puestos 
de trabajo con nombres muy diversos. Nos detendremos principalmente en los aspectos que pueden contribuir a clarificar la situación actual de nuestras titulaciones en relación a las exigencias del mercado laboral: la formación exigida en las ofertas de trabajo seleccionadas y las tareas y competencias a las que se asocian.

En segundo lugar, con el ánimo de lograr una mayor generalidad en las conclusiones obtenidas, se ha procurado recopilar una muestra de datos lo más amplia posible, sobrepasando ligeramente los 1700 registros. Se han incluido ofertas de trabajo tanto públicas (9'8\%) como privadas (90'2\%), sin establecer ninguna restricción inicial de carácter geográfico dentro del marco del estado español y con una amplitud temporal suficiente como para acoger ofertas de empleo sin que la muestra se viese afectada por factores coyunturales de cualquier índole. La desproporción entre la oferta pública y la oferta privada en 2012-2013 es reflejo de las circunstancias socioeconómicas que afectan a toda Europa.

El trabajo se estructura de la siguiente manera: tras esta introducción al objetivo y enfoque empleados, se describe más en detalle la metodología seguida, se analizan luego los resultados obtenidos a raíz de la muestra obtenida y se resumen finalmente las conclusiones alcanzadas en relación al objetivo inicial propuesto.

\section{METODOLOGÍA}

La recopilación de las aproximadamente 1700 ofertas de empleo anunciadas entre 2012 y 2013 se realizó a partir de los siguientes recursos:

> IWETEL: principal foro electrónico sobre bibliotecas y documentación en castellano.

$>$ COIE: Centro de Orientación en Información de Empleo de la Universidad Complutense de Madrid cuyo fin es favorecer la empleabilidad de los estudiantes y titulados de la UCM. Incluye entre sus servicios una Bolsa de Trabajo para los titulados de esta universidad.

$>$ RECBIB - Recursos Bibliotecarios: Portal (http://www.recbib.es) dirigido por Julián Marquina Arenas, una de cuyas finalidades principales es ofrecer información, de manera constante y actual, de trabajos y oposiciones dentro del ámbito de la Biblioteconomía, la Documentación y la Información en general.

$>$ QIPU:Plataforma (http://www.qipu.es) dirigida por José María Ortuño Fernández, dedicada a la publicación y difusión de contenidos para profesionales de la Información, incluyendo becas, prácticas y puestos de trabajo.

$>$ INQNABLE: Portal (http://www.inqnable.es) dirigido por José María Ortuño Fernández que incluye las convocatorias de oposiciones a Bibliotecas, Archivos, Museos y Centros de Documentación. 
Una vez extraídos los registros apropiados para nuestros objetivos y eliminadas las duplicidades existentes en las distintas bases de datos, se procedió a reorganizar la información disponible en cinco únicos campos:

$>$ Denominación del puesto de trabajo: Nombre bajo el cual se caracteriza la oferta de empleo.

$>$ Entidad: Organismo o centro que realiza la oferta de trabajo

$>$ Formación: Engloba tanto la titulación exigida como cualquier otro requisito vinculado al puesto demandado.

$>$ Tareas: Incluye las tareas o competencias que debe desarrollar el candidato en el puesto de trabajo.

$>$ Notas: Cualquier otra información de interés que aparezca en el anuncio.

Finalmente se hizo un recuento de los registros con idéntica denominación (salvo palabras vacías). A raíz de este recuento se obtuvieron las denominaciones más frecuentes sobre las que se efectuó el análisis.

\section{RESULTADOS}

Una vez realizada la recopilación de las ofertas de trabajo, unificados los registros correspondientes a una misma denominación y organizados los datos referentes a la formación, requisitos y tareas que debían desempeñar los candidatos a los distintos puestos ofertados, de las 1705 ofertas de trabajo se obtuvieron siete denominaciones principales : Community manager (8'6\%), Documentalista (6'2\%), Grabador de datos (3'3\%), Gestor de contenidos web (2'8\%), Auxiliar de biblioteca (2'3\%), Bibliotecario (1'7\%) y Digitalizador (1'6\%). Las siguientes denominaciones disminuyen abruptamente en frecuencia: Archivero (1\%), Vendedor de libros (0'9\%), Editor (0'8\%), Auxiliar Administrativo (0'7\%), y así sucesivamente. En resumen, solo estas siete denominaciones suman un 26 '5\% del total de ofertas, mientras que las aproximadamente ochocientas denominaciones restantes suman el 73'5\% de las ofertas consideradas.

A continuación se resumen los resultados obtenidos del análisis de cada una de estas denominaciones -expuestas en orden decreciente de frecuencia-, resaltando los aspectos relacionados con los factores enunciados previamente (formación, requisitos y tareas o competencias asociadas al puesto de trabajo):

\subsection{COMMUNITY MANAGER}

Las ofertas de trabajo bajo la denominación "Community Manager" (todas ellas de carácter privado) solicitan a los candidatos al puesto, en un porcentaje importante, una formación de ámbito universitario y nivel de Licenciatura (56’1\%). Dentro de este grupo, la demanda de licenciados no comporta en la 
mayoría de los casos la exigencia de una titulación específica (38’8\%), pero cuando la oferta de trabajo incluye una titulación concreta, dominan claramente los profesionales del ámbito de Ciencias de la Comunicación (Licenciatura en Periodismo -24\%-, Licenciatura en Publicidad y Relaciones Públicas -23’3\%- y Licenciatura en Comunicación Audiovisual -11’6\%-, ordenándolas en orden decreciente de número de ofertas).

A gran distancia de las licenciaturas, considerando el número de ofertas, figura una formación genérica de Diplomatura (8’7\%) y, por último, una formación de posgrado -6’1\%- (con un Máster específico en Community Manager o en Social Media en su caso).

Es muy frecuente que esta titulación vaya acompañada de otros requisitos formativos, entre los que destacan la formación específica en gestión y dinamización de redes sociales -un 74’1\% de las ofertas-. En un segundo grupo por frecuencia de aparición se sitúan el dominio de las tecnologías de la información -un 44'2\%- (destacando el diseño web, HTML, CSS, o las técnicas SEO y SEM), el conocimiento de herramientas informáticas específicas de gestión de sitios web y comunidades virtuales -12'2\%- (HootSuite, Radian6 o Google Analytics) y la familiaridad con el marketing digital (10’9\%), la promoción online (7’5\%), el diseño gráfico publicitario (6'1\%) o la publicidad digital (4’8\%).

Mención aparte merecen otros tres aspectos muy frecuentes en las ofertas de trabajo consideradas en este análisis y relacionados con la formación del candidato a estos puestos de community manager. El primero de ellos se refiere al dominio de idiomas -en un 47'6\% de las ofertas- (predominando el inglés, seguido del portugués, francés y alemán en el corpus considerado). El segundo de ellos alude al alto nivel exigido en la comunicación escrita y hablada (en un 37’4\% de las ofertas), no siendo infrecuente la exigencia de un nivel excelente de redacción en castellano y en otros idiomas. De igual forma, destaca la exigencia de experiencia previa en puestos de trabajo similares (un 46'7\% de las ofertas).

En relación a las tareas que tendría que desarrollar el candidato a ocupar estos puestos de trabajo, se pueden resumir en la siguiente enumeración (ordenadas de mayor a menor frecuencia):

> Creación, desarrollo, mantenimiento y dinamización de redes sociales, blogs corporativos y foros de opinión.

$>$ Promoción de productos y gestión de la publicidad creando campañas, noticias, notas de prensa y otras herramientas de comunicación (newsletters, por ejemplo).

$>$ Generación y redacción de contenidos web.

$>$ Gestión de la comunidad de usuarios.

$>$ Monitorización y seguimiento de los medios sociales (mediante medición y análisis de tendencias), así como el desarrollo de estrategias de Social Media. 
A modo de conclusión, los puestos de trabajo bajo la denominación “Community manager” poseen un núcleo claramente definido, relacionado con la gestión y dinamización de redes sociales, lo que implica el dominio de otras áreas de conocimiento de carácter técnico (tecnologías de la información) y de carácter lingüístico (comunicación oral y escrita). Estos aspectos complementarios vinculan a los expertos en community manager con otras denominaciones como "Posicionamiento web" o "gestión web", si consideramos su vertiente más tecnológica, y con denominaciones como "Gestor de contenidos web” o "Redactor de contenidos online” si lo enfocamos desde la perspectiva lingüística. Este bagaje simultáneo de conocimientos de espectro tan amplio (aunando saberes de carácter social, técnico y lingüístico) origina y en muchos casos fuerza la exigencia de experiencia anterior en el desempeño de dichas tareas.

\subsection{DOCUMENTALISTA}

Las ofertas de trabajo bajo la denominación de "Documentalista" requieren que los candidatos sean, en un porcentaje alto (31\%), Licenciados en Biblioteconomía y Documentación o Diplomados en la misma materia (27’6\%). En un porcentaje inferior se requiere que tengan la Formación Profesional de Grado Medio en Administración y/o Informática (6,9\%) y en otros casos la Formación Profesional de Grado Superior (5’2\%). Otras Licenciaturas del ámbito de las Humanidades -Periodismo, Historia, Economía, Derecho- también son demandadas aunque en mucha menor medida (3’4\%). La formación de tercer ciclo (doctorado) apenas es solicitada.

Aparte de la titulación específica, se solicita normalmente experiencia en puestos similares con anterioridad (de al menos 2 años) y en el conocimiento de gestores de contenidos. Igualmente se pide conocimiento de edición web -HTML, CSS, XML- (10’3\%), dominio del paquete Office (9,5\%), Excel avanzado (4’3\%), conocimiento de buscadores de noticias nacionales e internacionales, conocimiento de SAP, de blogs, wikis y redes sociales, de legislación de archivos, de estándares del sector (MARC21, IBERMARC, ISBD, DUBLIN CORE, LINKED DATA) y, por supuesto, experiencia en bases de datos.

En casi todos los puestos es muy valorado el conocimiento de idiomas, principalmente un alto nivel de inglés hablado y escrito (35’9\%). Sólo en determinados casos se pide que el candidato sea bilingüe. También el conocimiento de francés es solicitado así como los idiomas alemán y portugués. Para ciertos puestos a desempeñar en Cataluña se requiere el conocimiento del catalán.

Entre las tareas a desarrollar por los candidatos podemos destacar, en orden de prioridad, las siguientes:

Búsqueda e investigación en bases de datos

$>$ Búsqueda y recuperación de información

$>$ Carga de contenidos en gestores documentales 
$>$ Evaluación y análisis de la cadena documental

$>$ Expurgo de documentación existente

$>$ Gestión y catalogación de documentación

$>$ Parametrización del repositorio documental

$>$ Redacción de contenidos

$>$ Tratamiento de imágenes, sistemas de gestión de bases de datos, tecnologías web y lenguajes de marcación XML

Mención aparte merecen otras características o notas que se aprecian en la oferta de los perfiles de Documentalista. La experiencia en puestos similares es algo que generalmente se pide cuando se ofrecen estos puestos (mínima de un año y hasta cuatro es exigible). Es frecuente que se pida estar en posesión del carné de conducir (aunque no con vehículo propio) y con disponibilidad inmediata para incorporarse al puesto. A menudo las ofertas se presentan en cualquier lugar de la geografía española e incluso en el extranjero. Otra de las cualidades exigidas es que el candidato sea una persona organizada y dinámica.

A modo de conclusión, el perfil del Documentalista se presenta como el del profesional cualificado, con estudios superiores, capaz de gestionar y organizar la documentación tanto en el ámbito de la localización de la misma como de su recuperación, organización y tratamiento posterior. También será capaz de gestionar esa información en páginas web y todo lo que conlleva el uso de las nuevas tecnologías y plataformas de comunicación (redes sociales, etc). A más distancia, pero sin olvidarlo, el archivo será igualmente otra de las competencias del documentalista y la correcta clasificación de los documentos en el mismo.

\subsection{GRABADOR DE DATOS}

Analizando las ofertas de trabajo bajo la denominación "Grabador de datos" encontramos, en un porcentaje muy alto, que la formación que se requiere a los candidatos es tener finalizada la Formación Profesional de Grado Medio o la de Grado Superior, destacando la Espacialidad de Administración y finanzas (46,8\%), seguida no muy de lejos por la Educación Secundaria Obligatoria (ESO) y/o el Bachillerato (35'5\%), no siendo en su mayoría los estudios de Documentación, ni la Diplomatura, Licenciatura ni el Grado, los estudios requeridos para la realización de este puesto de trabajo (1’6\%), aunque sí encontramos ofertas que requieren, de forma complementaria, conocimientos en la preparación de documentación, por ejemplo en documentación médica y digitalización (6’5\%). Es significativo que algunas empresas requieren candidatos sin estudios ( $3{ }^{\prime} 2 \%$ ).

También, en algunas ofertas, se precisa tener altos conocimientos de idiomas (hablado y escrito), sobre todo inglés (6,5\%), aunque también se solicita francés (4’8\%), portugués y alemán (3’2\%), italiano y catalán (1’6\%). 
Entre los conocimientos que se requieren sobresale el perfecto uso de los programas de ofimática como el Excel, Word y Access, que son los más comunes en el mercado como hoja de cálculo, procesador de textos y generador y administrador de bases de datos (22’6\%). En algunas ofertas hemos encontrado la necesidad de que el candidato domine otros programas específicos para ese puesto o empresa como las herramientas de fotografía Kodak, SQL, software de gestión de empresa SAP, además de conocimientos relacionados con el negocio de la empresa como jurídicos, ferroviarios, deportivos, etc.

Continuando con la formación se valora mucho la experiencia en un puesto similar, entre uno y tres años (29\%), y sobre todo mucha rapidez en las pulsaciones de un teclado, entre 180 y 300 pulsaciones por minuto (53'2\%), informando al candidato que se realizará prueba de nivel de velocidad.

Como curiosidad en algunas ofertas se requiere que el candidato tenga carnet de conducir y sobre todo vehículo propio (11’3\%), ya que muchas de estas ofertas de empleo están ubicadas fuera de las grandes ciudades donde las empresas tienen sus oficinas.

En cuanto a las tareas a desarrollar, las ofertas nos indican que prevalece la grabación de datos, tanto alfanuméricos o solo numéricos, aunque también se realizan tareas de digitalización, archivo, recopilación y verificación de datos, atención a clientes.

Las ofertas, en un porcentaje muy alto, requieren disponibilidad inmediata para comenzar a trabajar $\left(25^{\prime} 8 \%\right)$ y demandan una persona dinámica, responsable, metódica, con iniciativa, capacidad de aprendizaje, rapidez y ganas de aprender.

Por la información recopilada, son muy diversos los tipos de empresas que requieren los servicios de los grabadores de datos, y la disponibilidad para trabajar en turnos, jornada completa partida o jornada de mañana o tarde, incluso horas sueltas.

Para finalizar observamos que las retribuciones ofrecidas e indicadas en las ofertas de trabajo están entre 600 y 900 euros, no sobrepasando los 1000 en ningún momento.

Como conclusiones finales indicar que el puesto de trabajo "Grabador de datos" tiene sus funciones y requerimientos claramente establecidos, dando mucha importancia a la rapidez en el mecanografiado, debiendo conocer, en segundo lugar de importancia programas de tratamiento de textos, hojas de cálculo o generadores de bases de datos, junto a los programas específicos empleados en la empresa; también se le da mucha importancia a los idiomas, aunque en menor medida. No encontramos una relación directa con los estudios de documentación, ya que no se requiere tener conocimientos específicos sobre el tema, aunque en ocasiones, según aparece en las ofertas, el candidato deba atender el archivo y digitalizar documentos, lo que conlleva la descripción, aunque sea abreviada, de los documentos digitalizados y su organización en el archivo. 


\subsection{GESTOR DE CONTENIDOS WEB}

Las ofertas de trabajo con la denominación "Gestor de contenidos web” requieren candidatos que tengan una formación que va desde la Formación Profesional Grado Superior, en menor medida el Grado Medio (19’5\%), y después destacan muchas ofertas en las que se requieren Licenciados en Administración y Dirección de Empresas, Marketing, Periodismo y Documentación, incluso solicitando Diplomados en Biblioteconomía y Documentación (73’2\%). No hemos visto que se requiera haber realizado un Máster para acceder a un puesto de estas características.

Observamos que el conocimiento de idiomas para este puesto tiene un valor mayor, ya que se requiere tener un nivel medio y alto en inglés (36'6\%), aunque también hemos encontrados ofertas en las que se requiere portugués (7’3\%), italiano (4’9\%), catalán y francés (2’4\%).

Respecto a los conocimientos en determinados software observamos que el candidato debe conocer procesadores de texto (17'1\%), herramientas de diseño photoshop o similar- (9'8\%), diseño Web -Dreamweaver, HTML o similar- (41'5\%), todo encaminado a la creación, actualización y mantenimiento de portales web.

Las ofertas requieren, en su mayoría, de una experiencia de entre dos a tres años como media en un puesto similar, con buen manejo de informática, internet, correo electrónico, buscadores, herramientas de comunicación online, etc. (19’5\%).

Las tareas a desarrollar por los candidatos pasan por actualizar todos los contenidos de las páginas web y redes sociales, control de calidad de los contenidos, la creación y redacción de textos, creación de newsletters, elaboración de manuales de formación, corrección de estilo e inserción de textos, redacción de notas de prensa, traducciones, edición de imágenes, atención telefónica y gestión del correo diario.

Las ofertas requieren de una persona proactiva, creativa, responsable, organizada, apasionada por Internet, paciente, comunicativa y con gran capacidad para trabajar en equipo.

En algunas ofertas se requiere permiso de conducir, que tenga permiso de trabajo y sobre todo disponibilidad inmediata.

Como conclusiones sobre esta denominación "Gestor de contenidos web" indicamos que el candidato debe tener conocimientos en informática e Internet destinados a la creación y actualización de contenidos webs, de alguna forma relacionado también con las redes sociales.

En cuanto a los conocimientos requeridos para este puesto observamos que algunos de ellos ya se imparten en nuestro grado, es decir todo lo relacionado con la informática, creación de páginas web, aunque se carece de temario sobre edición, tratamiento de imágenes, corrección de estilo, algo que se podría cubrir con alguna asignatura optativa que se ofertara. 


\subsection{AUXILIAR DE BIBLIOTECA Y BIBLIOTECARIO}

Las ofertas de trabajo bajo la denominación genérica de Bibliotecas son muy extensas, y van desde el puesto de Director al de auxiliar, becario o a la realización de prácticas, pasando por el administrativo, catalogador, coordinador, monitor, etc..., lo que demuestra que en muchas ocasiones el empleador no tiene muy claras las funciones que debe realizar la persona buscada ni tampoco el nombre que se debe dar a su puesto de trabajo. En nuestro caso el nombre específico que más se solicita es el de Auxiliar de Biblioteca, seguido del de Bibliotecario, pero también aparece con frecuencia el de Ayudante de Biblioteca, el de Encargado de Biblioteca, o el de Técnico de Biblioteca (con la denominación de auxiliar, especialista, medio o superior), lo que avala lo dicho anteriormente sobre el problema del nombre del puesto de trabajo y las funciones a desarrollar, que en muchas ocasiones son las mismas para distintos puestos, e incluso en otras el empleador se limita a decir que son "las propias del puesto", dejando sin especificar las tareas a realizar.

Centrándonos en las referencias específicas de Auxiliar de Bibliotecas y Bibliotecario, hay que decir que se mantiene en cierta medida la confusión antes citada, en general para el Auxiliar de Biblioteca la oferta es fundamentalmente pública -ayuntamientos sobre todo- (87’3\%), y en estos casos la formación solicitada es siempre una de estas opciones: Formación Profesional (normalmente FP2), Graduado en ESO o Bachiller; solo en alguna de las ofertas privadas (12'7\%) la formación requerida se centra en los estudios de Diplomado en Biblioteconomía y Documentación o Licenciado en Documentación (3’2\%), añadiendo alguna referencia a una formación específica en el manejo de sistemas como Absysnet, Absys, y siempre una alusión a tener experiencia en la atención al público o bien en tareas relacionadas con el trabajo.

En el caso del Bibliotecario las ofertas son casi equivalentes en el sector público (55’2\%) y el privado (45'8\%); en el sector privado se pide casi en la totalidad de las ocasiones el título de Diplomado o Licenciado en Biblioteconomía y Documentación (88’7\%), es decir, se pide una formación académica mayor, en general hay bastantes referencias a la necesidad de contar con la Diplomatura en Biblioteconomía y Documentación, la Licenciatura en Documentación o, de forma genérica, una Licenciatura en Humanidades. Sólo en un caso se solicita poseer un Máster específico. Pero en las ofertas públicas se sigue manteniendo de forma reiterada el genérico de graduado, licenciado o similar, sin especificar nuestros estudios salvo en contadas ocasiones (1’2\%).

En cuanto a las tareas a desarrollar son muy variadas, pero las más repetidas son las de ordenar, catalogar y clasificar los fondos, seguida del préstamo y revisión de fondos, así como la indización y la revisión de los registros bibliográficos, para lo cual se suele exigir el conocimiento de herramientas como 
UNICORN, MARC21 (AMICUS, KOHA). En la gran mayoría de los casos de ambos puestos se solicita haber tenido experiencia profesional previa.

También hay que decir que un gran número de ofertas de trabajo relacionan directamente las Bibliotecas y los Archivos, solicitando a una persona que se ocupe de ambas tareas. Así hay numerosas solicitudes de Técnicos de archivos y bibliotecas (la mayor parte auxiliares, pero también alguna de técnica superior), y de Ayudantes de archivos y bibliotecas (a los que en ocasiones se añade también de museos), sin dejar de mencionar a los administrativos de Bibliotecas y Archivos, auxiliares, vigilantes e incluso la referencia al puesto de Archiveros Bibliotecarios (facultativos, responsables o incluso jefes de área), lo que demuestra que en muchos lugares ambos espacios conviven de forma conjunta a pesar de su clara diferenciación académica, profesional y estructural.

Para terminar, añadir unas pocas palabras para indicar que aunque en el listado de puestos más demandados no aparece ninguna referencia específica a los Archivos, el grupo de solicitudes de puestos de trabajo relacionados con el mundo de los archivos es también muy amplio, no sólo las “dobles” relacionadas con las bibliotecas, sino también las específicas de estos centros, que van desde el puesto de Director al de mozo, hay un buen número de solicitudes de Archiveros, además de administrativos, auxiliares y técnicos, con distinto perfil y nombre, cuyas tareas son en ocasiones muy imprecisas o bien se cruzan entre las distintas ofertas.

\subsection{DIGITALIZADOR}

En cuanto a la solicitud de Digitalizador, hay que decir que es una de las más demandadas, ya que a las propias con esta denominación hay que añadir todas aquellas que llevan un apellido específico añadido a la oferta de trabajo (técnico, de datos, documental, de fondos bibliográficos, de fondos antiguos, de documentación administrativo, de historias clínicas, etc...). En todos los casos la oferta es en su totalidad privada. La formación que se pide mayoritariamente para ocupar este puesto es la Formación Profesional de Grado Medio -y en menor medida la superior(71’7\%), a continuación la ESO o Bachillerato (23’3\%), y sólo en casos muy específicos la Diplomatura en Biblioteconomía y Documentación (3’3\%) o la Licenciatura en Documentación (1'6\%), siendo siempre muy valorada o incluso imprescindible la experiencia profesional previa en estos puestos de trabajo. Otros requisitos valorados son el conocimiento de distintas herramientas informáticas (MADRAS, EPOSCAN, INVESDOC, SMALWORLD, ICT, GIS), y el manejo de cámaras y escáneres (a veces muy específicos, añadiendo modelos y marcas).

En cuanto a las tareas a desempeñar van desde las tareas auxiliares, como desgrapado de documentos o mover cajas, al tratamiento y clasificación de documentos o al tratamiento de imágenes, aunque las más repetidas son dos, una que va unida al nombre del puesto, digitalización de documentos, y otra más genérica, grabador de datos, que lo relaciona con otros puestos de trabajo cuya 
denominación específica es precisamente esta, Grabador de Datos, lo cual nos lleva de nuevo a comentar la confusión del empleador al demandar un puesto específico, ya que lo denomina de distintas maneras, cuando las funciones a desarrollar son las mismas.

\section{CONCLUSIONES}

De los resultados obtenidos a raíz del análisis de las ofertas consideradas podemos concluir, en primer lugar, que los empleadores tienden a concebir más apropiada para los puestos de trabajo relacionados con la gestión de información en Internet (Community manager o Gestor de contenidos web, por ejemplo) una formación afín a Ciencias de la Información, a Informática y a Administración y Marketing, en detrimento de una formación en Biblioteconomía y Documentación. En relación a nuestras titulaciones, en las ofertas no se demandan los actuales estudios de grado debido a que la implantación de este título se realizó mayoritariamente en el curso 2009-2010, con lo que esta nueva formación no era todavía suficientemente conocida, tanto por los empleadores públicos como privados.

En cambio, las ofertas analizadas muestran que los empleadores siguen prefiriendo la formación en Biblioteconomía y Documentación cuando el puesto de trabajo está vinculado al tratamiento y gestión de documentos $\mathrm{y}$, en consecuencia, a las tareas tradicionales de documentalista, bibliotecario y archivero. Estas conclusiones confirman los resultados obtenidos con carácter general en análisis anteriores (Abadal, 2012). En relación a las causas de este fenómeno, se ha manifestado en ocasiones que la dependencia que siguen mostrando nuestros títulos académicos del mundo bibliotecario no facilita una visión moderna y proactiva de nuestros profesionales, favoreciendo en cambio una consideración básicamente tradicional de nuestro quehacer laboral, centrada en el documento, su mantenimiento y su localización (Currás, 2009).

También se observa una tendencia a aunar en un único puesto el desempeño de varias de estas tareas vinculadas a nuestros profesionales (documentalista y archivero, bibliotecario y archivero, por ejemplo). Desde el punto de vista del mercado laboral en los últimos años, pues, parecen difuminarse en cierta medida las profesiones de documentalista, bibliotecario y archivero, asignando al profesional, a grandes rasgos, la tarea de procesar y gestionar toda la documentación existente en la organización, sea cual sea su carácter.

En relación a las competencias profesionales exigidas y los contenidos del grado en Información y Documentación, podemos concluir con carácter general que se debería incorporar a los planes de estudio de grado el aprendizaje de los nuevos procedimientos de gestión de la información y documentación adaptados a los avances de la informática y de las tecnologías de la información y comunicación. A este respecto pueden destacarse el aprendizaje de herramientas informáticas ampliamente utilizadas en los puestos de trabajo (Absys, HootSuite o 
SAP, entre otras) y el dominio de los modos recientes de difusión y gestión de la información en Internet, que en ocasiones provoca la aparición de nuevos puestos de trabajo muy demandados (community manager, gestor de contenidos, curaduría digital o e-administración, por ejemplo).

Es muy frecuente, igualmente, que se requiera de los candidatos a estos puestos de trabajo no solo una formación añadida en el dominio de idiomas-predominando el inglés entre una gran variedad de lenguas extranjeras-, sino en especial una gran pericia en la expresión escrita -tanto del idioma materno como del idioma requerido para el puesto-. Aunque no son competencias de carácter estrictamente informativo o documental, concluimos que estos aspectos -dada la importancia concedida a ellos en las ofertas de trabajo consideradas- podrían ser reforzados en futuras revisiones del grado.

Estos aspectos lingüísticos relacionados con la creación y redacción de textos, muy frecuentes en los puestos donde prima la información frente a la documentación (community manager, content curator o gestión de contenidos web, entre otros) podrían ser uno de los motivos de la preponderancia en la demanda de titulados en Ciencias de la Información (Periodismo o Publicidad y Relaciones Públicas principalmente) frente a los profesionales especializados en Biblioteconomía y Documentación en las ofertas analizadas, dado que estas competencias lingüísticas son relevantes en dichas titulaciones.

Destacar finalmente la exigencia abrumadora de experiencia previa en el desempeño del trabajo ofertado. Quizá la falta de una formación específica en competencias de carácter tan variado y disperso desde la perspectiva académica-aunando los aspectos tecnológicos, lingüísticos, informativos y documentales-justifique en parte este requisito. Desde el punto de vista del empleador lo relevante es el desarrollo eficaz de las tareas encomendadas. Pero si no existe una titulación que garantiza la adquisición de todas las competencias necesarias, la opción más segura consiste en la demostración de que se han realizado dichas tareas previamente.

\section{AGRADECIMIENTOS}

Queremos agradecer la colaboración desinteresada de Tomás Baiget, José María Ortuño Fernández y Julián Marquina Arenas, por facilitarnos el acceso a los datos conservados en los recursos que dirigen.

\section{REFERENCIAS BIBLIOGRÁFICAS}

ABADAL, Ernest (2013). "La Biblioteconomía y la Documentación en la universidad española a principios del siglo XXI”, Nuovi annali della Scuola speciale per archivisti e bibliotecari, Anno XXVII, pp. 211-228. 
ABADAL, Ernest; BORREGO, Ángel; SERRA PÉREZ, Rafael (2012). “Mercado laboral de profesionales de la información: evolución de la oferta y de los perfiles ocupacionales”, en BiD: textos universitaris de biblioteconomía i documentació, n 29. http://bid.ub.edu/es/29/abadal2.htm [Consulta: 14-11-2014]

BAIGET, Tomás (2012). "Profesionales de la información. Un futuro de oportunidades”, en FERNÁNDEZ BAJÓN, María Teresa (coord.) Dos décadas de Información y Documentación: De la Escuela Universitaria de Biblioteconomía y Documentación a la Facultad de Ciencias de la Documentación (1991-2010). Madrid: Facultad de Ciencias de la Documentación UCM, pp. 211-230.

BORREGO, Ángel; COMALAT, Maite; ESTIVILL RIUS, Assumpció (2004). "Inserció laboral dels titulats en Biblioteconomia i Documentació per la Universitat de Barcelona”. BiD: textos universitaris de biblioteconomía $i$ documentació, $\mathrm{n}^{\circ}$ 12. http://bid.ub.edu/12/martin2.htm [Consulta: 14-11-2014]

CARIDAD, Mercedes; MARTÍN, Bonifacio; MÉNDEZ, Eva; RODRÍGUEZ, David (1999). "Breve panorama actual sobre la Documentación en España (excepto Cataluña)", en Bibliodoc: anuario de Biblioteconomía, Documentación e Información, pp. 233-260.

CURRÁS, Emilia (2009). "El documentalista en crisis”, en El profesional de la información, v. 18, $\mathrm{n}^{\circ}$ 4, pp. 421-423.

INFORMATION Professionals 2050: Educational possibilities and pathways (2012). Edited by MARCHIONINI, Gary and MORAN, Barbara B. Chapel Hill, School of Information and Library Science. http://sils.unc.edu/sites/ default/files/publications/Information-Professionals-2050.pdf [Consulta: 1411-2014]

MARTÍN GONZÁLEZ, Yolanda; TRAVIESO RODRÍGUEZ, Críspulo; RÍOS HILARIO, Ana Belén; HERNÁNDEZ OLIVERA, Luis; CARO CASTRO, Carmen (2014). "La inserción profesional de los graduados en Información y Documentación: el caso de la Universidad de Salamanca”, en BiD: textos universitaris de biblioteconomía i documentació, nº 32. http://bid.ub.edu/es/32/ martin2.htm [Consulta: 14-11-2014]

MERLO-VEGA, José Antonio; GÓMEZ-HERNÁNDEZ, José Antonio; HERNÁNDEZ-SÁNCHEZ, Hilario (2011). Estudio FESABID sobre los profesionales de la información: prospectiva de una profesión en constante evolución. Madrid: FESABID.

MONTES LÓPEZ, Evelio (1995). "El mercado de trabajo de los documentalistas en España: análisis de una muestra de ofertas de empleo, 1984-1994”. Revista española de documentación científica, vol. 18, $\mathrm{n}^{\circ} \quad 2$, pp. 178-187. http://redc.revistas.csic.es/index.php/redc/article/viewArticle/655 [Consulta: 14-11-2014]

MOREIRO-GONZÁLEZ, José Antonio (2001). "Figures of employability of Spanish library and information science graduates”, en Libri, vol. 51, n ${ }^{\circ}$, pp. 27-37. 
MOREIRO-GONZÁLEZ, José Antonio; SÁNCHEZ-CUADRADO, Sonia; MORATO-LARA, Jorge; TEJADA-ARTIGAS, Carlos-Miguel (2009). "Creación de un corpus de competencias en información y documentación a partir de ofertas de empleo en España”, en Revista ibérica de sistemas y tecnologías de información(Risti), v. 3, pp. 79-91. http://www.aisti.eu/ risti/RISTI\%20N3.pdf [Consulta: 14-11-2014]

ORTIZ-REPISO, Virginia; CALZADA-PRADO, Javier; APORTELARODRÍGUEZ, Ivett M. (2013). “¿Qué está pasando con los estudios universitarios de Biblioteconomía y Documentación en España?”, en El profesional de la información, vol. 22, nº 6, pp. 505-514. 